\section{Salt and Meal-Salt Help Distribute Cattle Use on Semidesert Range}

\section{S. CLARK MARTIN AND DONALD E. WARD}

Highlight: Cows on semidesert grass-shrub range ate less than $1 / 2 \mathrm{lb} /$ day of $3: 1$ mealsalt mix when it was fed 1 to $2 \frac{1}{2}$ miles from water. No injury to cattle due to either inadequate or excessive salt intake was observed. Compared to feeding at water, placing salt or meal-salt 1 to $2 \frac{1}{2}$ miles from water increased average utilization of perennial grasses where use was usually light, but it did not materially decrease use near water.

Forage is rarely used uniformly and properly because cattle usually go no farther than they must to get their fill, and they prefer flat, soft ground to steep, rocky terrain. They have definite preferences among forage species, and will regraze their favorite plants repeatedly rather than consume less palatable herbage that is more abundant.

Range managers have used fencing, water, and trail development, complex grazing rotations, and other tools to distribute cattle more evenly over the range. Placing salt where heavicr use is desired is one of the easiest and cheapest methods of improving livestock distribution-if it works. The successes obtained by this method, however, have been mixed.

Chapline and Talbot (1926) reported that salt could be an economical aid in the local distribution of cattle. Ares (1936) found that feeding salt away from water reduced the length of time cattle hung around water, increased the area of the range receiving proper use, and decreased the percentages of heavy and light use on level rock-free range in southern New Mexico. Feeding meal-salt mix away from water only, likewise resulted in a larger properly used area and smaller areas of heavy and light use than did feeding meal-salt both at water and away (Ares, 1953). Skovlin (1965), in Oregon,

\footnotetext{
Authors are principal range scientist and range scientist, Rocky Mountain Forest and Range Experiment Station, Forest Service, U. S. Department of Agriculture, Tucson, Arizona. The station maintains central headquarters at Fort Collins, in cooperation with Colorado State University.
}

Manuscript received February 26, 1972. found that cattle required little salt above that in forage to meet minimum nutritional needs, but that their appetite for salt compelled them to use it. Cattle took salt daily in the summer and every 2 to 3 days in cooler seasons. Cattle generally took salt during their grazing period and did not go directly from salt to water. Bentley (1941) placed salt 3/4 mile from water on California bunchgrass range and observed that cattle averaged more than 7 hr between salt and water. Ares (1936) observed that when salt was fed away from water, cattle licked salt then left to graze in a direction opposite from water. On the Santa Rita Experimental Range, with salt placed at water, Culley (1938) and Zemo and Klemmedson (1970) found that cattle usually visited the salt block after drinking, then went to graze. These results indicate that placing salt away from water does not hurt cattle either by depriving them of adequate salt or by making them thirsty.

It is common practice to limit consumption of protein supplements on the
Table 1. Schedule for placement of salt and meal-salt. range by including one part salt to about three parts supplement. When fed at water on a free-use basis, meal-salt mixtures usually are consumed at a rate of about $2 \mathrm{lb}$./day per animal. A recommended precaution in use of meal-salt mixtures is that cattle should have adequate water (Cardon et. al., 1951). Cattlemen have been reluctant to place mealsalt mixtures away from water because cattle can get sick or die if they do not get water soon enough after eating large amounts of mixture. When $80 \%$ meal-salt mix was fed $1 / 2$ to 3 miles from water in southern New Mexico, however, yearling cattle ate not more than $1 / 2 \mathrm{lb}$. of the mixture per day and exhibited no ill effects (Ares, 1953).

This study was undertaken to determine (1) whether salt or meal-salt mixtures were effective in improving distribution of grazing use, and (2) whether livestock were affected detrimentally by placing either salt or meal-salt at remote locations on semidesert range. Topography, rainfall, and vegetation at these remote locations were substantially different from those of earlier studies.

\section{Study Area and Methods}

The study was conducted in pasture 15 on the Santa Rita Experimental Range near Tucson, Ariz. The pasture is served by one permanent water; the greatest distance from water to forage is about 3 miles. Continuous year-long grazing since 1930 has reduced the stand of perennial grasses and increased the abundance of annuals near water (Fig. 1). The range is mostly flat to gently sloping, but a number of shallow, steepsided canyons and water courses interfere with livestock movements.

The bulk of the study area lies between 3,200 and $3,800 \mathrm{ft}$ elevation. Average annual precipitation is from 13 to 15 inches, with 7 to 8 inches falling during the summer growing period. Effective rainfall from April to June is rare, and May and June are especially hot and

\begin{tabular}{|c|c|c|c|c|c|c|}
\hline Schedule & Station & $\begin{array}{l}\text { Distance from } \\
\text { water (miles) }\end{array}$ & Item fed & 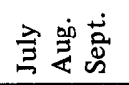 & 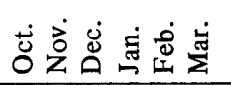 & 芶勇恶 \\
\hline 1 & S1 & 0 & Salt & X X X & $\mathrm{X} \times \mathrm{X} \times \mathrm{X} \times$ & $\mathrm{X} \times \mathrm{X}$ \\
\hline 2 & $\begin{array}{l}\text { S2, S3 } \\
\text { S4, S5 }\end{array}$ & $\begin{array}{l}1 \text { to } 1^{1 / 2} \\
1 \frac{1}{2} \text { to } 2 \frac{1}{2}\end{array}$ & $\begin{array}{l}\text { Salt } \\
\text { Salt }\end{array}$ & 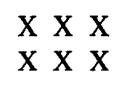 & $\mathrm{X} \times \mathrm{X} \times \mathrm{X} \mathrm{X}$ & $\begin{array}{llll} & X & X & X \\
X & X & X\end{array}$ \\
\hline 3 & S1 & $\begin{array}{l}0 \\
0\end{array}$ & $\begin{array}{l}\text { Salt } \\
\text { Meal-Salt }\end{array}$ & X X X & $\begin{array}{llllll}X & X & X & X & X & X \\
X & X & X & X & X\end{array}$ & $\begin{array}{l}\mathrm{X} x \mathrm{X} \\
\mathrm{X}\end{array}$ \\
\hline 4 & $\begin{array}{l}\text { S2, S3 } \\
\text { S4, S5 }\end{array}$ & $\begin{array}{l}1 \text { to } 1^{1 / 2} \\
1 \text { to } 1 \frac{1}{2} \\
1^{1 / 2} \text { to } 2 \frac{1 / 2}{2} \\
1^{1 / 2} \text { to } 2 \frac{1}{2}\end{array}$ & $\begin{array}{l}\text { Salt } \\
\text { Meal-Salt } \\
\text { Salt } \\
\text { Meal-Salt }\end{array}$ & $\begin{array}{l}\mathrm{X} \times \mathrm{X} \\
\mathrm{X} \times \mathrm{X}\end{array}$ & $\begin{array}{llllll}X & X & X & X & X & X \\
X & X & X & X & X & X\end{array}$ & $\begin{array}{lll}\mathbf{X} & \mathbf{X} & \mathrm{X} \\
\mathrm{X} & \mathbf{X} & \mathbf{X}\end{array}$ \\
\hline
\end{tabular}




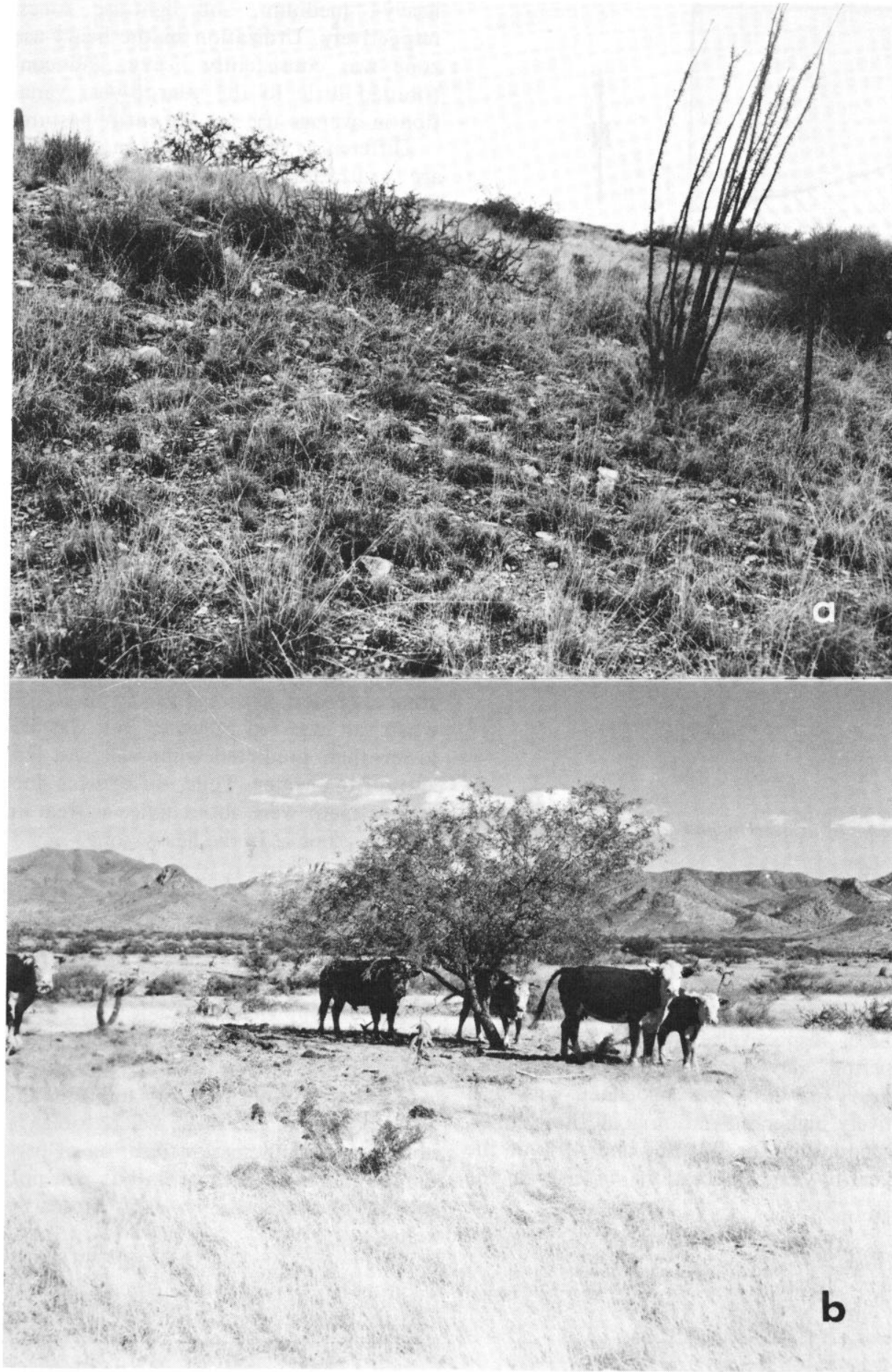

Fig. 1. Past grazing has changed the vegetation. Long-lived perennial grasses dominate lightly used range far from water (a), but have been replaced by short-lived perennials and annuals near water where use is always heavy (b).

dry.

Vegetation is a desert-shrub type dominated by a sparse stand of velvet mesquite (Prosopis juliflora var. velutina). Other important shrubs include catclaw acacia (Acacia greggi), white-thorn ( $A$. constricta), burroweed (Aplopappus tenuisectus), blue palo-verde (Cercidium floridum), desert zinnia (Zinnia pumila), pricklypear (Opuntia engelmannii), and

\section{bolus contractus).}

Major annual grasses are six-weeks threeawn (A. adscensionis) and needle grama (B. aristidoides).

Four schedules of feeding salt or salt in combination with $3: 1$ meal-salt mixture (3 parts cottonseed meal - 1 part salt) were used. These were: (1) block salt at water yearlong, (2) block salt away from water yearlong, (3) block salt at water yearlong with meal-salt added November-April, (4) block salt away from water year-long with meal-salt added October-June. The treatment year was July 1 through June 30 . Each schedule was used for 1 year during the first 4 years of the study period, and again in the second 4-year period. Meal-salt troughs were refilled weekly. Block salt was always available where meal-salt was fed. Salt served as a standby attractant for cattle when the meal-salt mixture ran out between feeding dates.

Meal-salt was not fed July-September because supplemental feed is rarely needed or used during this period. Mealsalt feeding began 1 month earlier and ended 2 months later when placed away from water than when placed at water. This longer feeding period was used to maximize the effects of placing meal-salt away from water. Feeding meal-salt at water November-April conforms more nearly to common practice in which feeding rarely starts before December and is stopped as soon as spring growth of herbage or browse is available.

Five salt, meal-salt stations were established (Fig. 2). Station $\mathrm{S} 1$ was at the water. Intermediate stations (S2 and S3) were 1 to $1-1 / 2$ miles from water. Far-out stations (S4 and S5) were $1-1 / 2$ to $2-1 / 2$ miles from water in areas used least frequently by cattle. These far-out stations were supplied, as scheduled, with salt or meal-salt October-March or with salt only July-September. Placement of salt and meal-salt under each schedule is indicated in Table 1.

Twenty-seven 1/4-mile-long paced transect courses were established. Transects were oriented at right angles to the direction to water. Utilization of each major perennial grass species was estimated by the ungrazed plant method (Roach, 1950); herbage production was estimated ocularly on ten, 1.0 - by $9.6-\mathrm{ft}$ plots equally spaced along the 1/4-mile transects. One or two herbage plots per transect were clipped to provide regression data for adjusting ocular estimates and to provide samples for dry-weight determinations. Utilization was measured three times a year around October 1 , April 1, and June 1. Herbage production was estimated around October 1 .

At the end of the 8-year period, the transects were ranked in order of average utilization in June. The area containing 


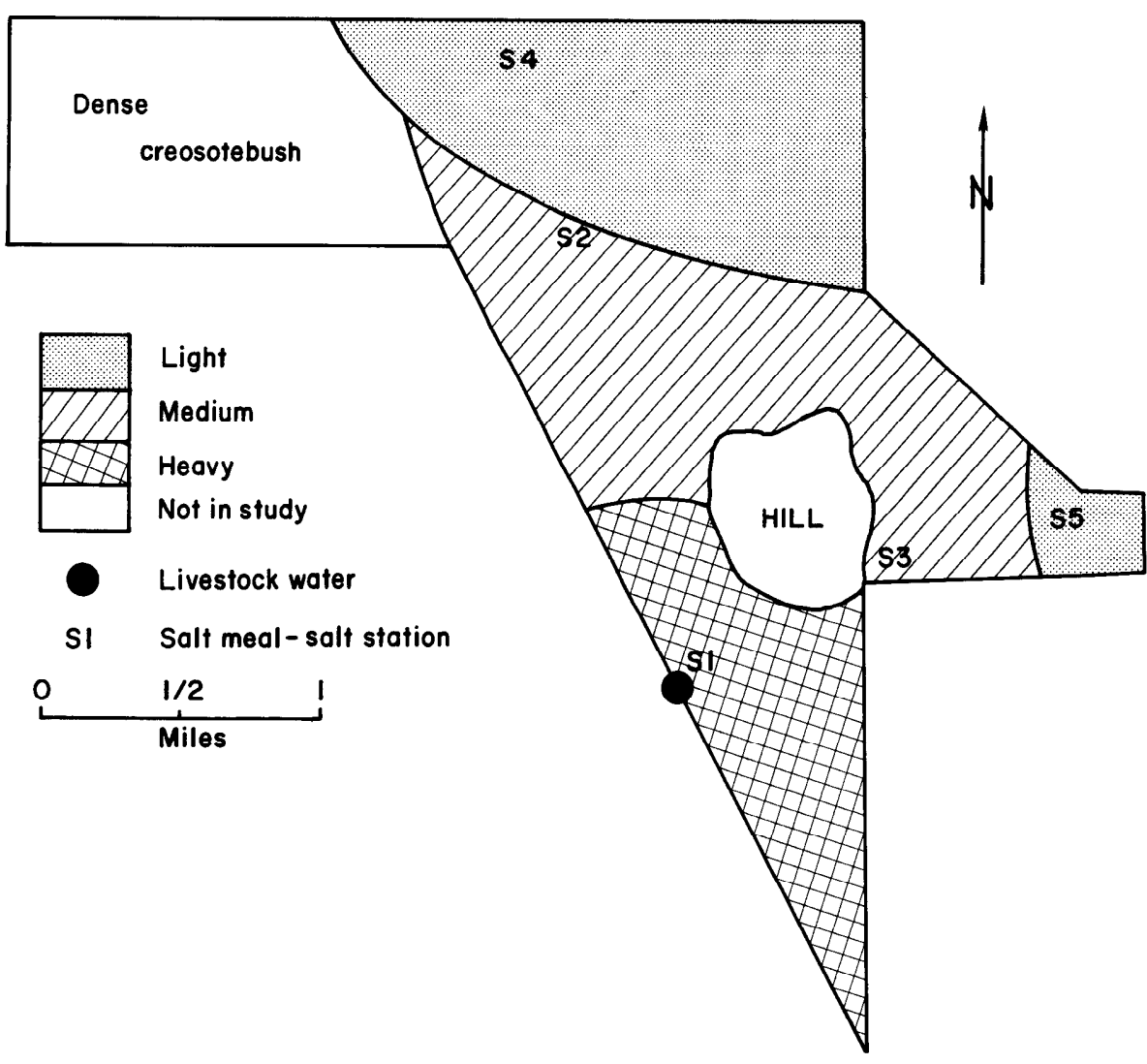

Fig. 2. Locations of water, salt meal-salt stations, zones of utilization, and areas not sampled.

the nine most heavily grazed transects was then designated as the heavy-use zone, that containing the nine intermediate transects as the medium-use zone, and the area with nine most lightly grazed transects as the light-use zone (Fig. 2). Replications were the first 4 and the last 4 years of the study. Analyses of variance and linear regressions were used to evaluate differences in utilization among zones and treatments.

\section{Results}

When the meal-salt mix was fed at water, cattle consumed about $2 \mathrm{lb}$./day per animal. When fed a mile or more from water, average consumption for all cattle in the pasture was less than $1 / 2 \mathrm{lb}$./day. We saw no evidence of salt sickness or toxicity. These results are similar to Arcs' (1953) findings on black grama range in New Mexico. If green herbage was available, consumption of meal-salt was negligible. Apparently there is little danger of cattle gorging themselves on meal-salt when it is placed a mile or more from water in the presence of ample herbage. In some situations, however, low consumption itself could be a problem. If it is essential that animals take $2 \mathrm{lb}$. of supplement daily to meet minimum nutritional requirements, $3: 1$ meal-salt mixtures placed a mile or more from water heavy-, medium-, and light-use zones, respectively. Utilization in the heavy-use zone was consistently heavy, and contributed little to the year-to-year variation in average use for the entire pasture.

Differences between years in the average utilization for the pasture and in distribution of use were not affected significantly by placement of salt or meal-salt, but several trends were evident. The strongest treatment effect was increased utilization in the light-use zone when salt or meal-salt was fed away from water (Fig. 3). The effects of placement of meal-salt on distribution of use in the heavy- and medium-use zones were largely obscured by variations in forage production.

When the amount of perennial grass available per animal unit was used to predict utilization, actual use in the lightuse zone was $10 \%$ lower than predicted when salt was fed at water and 12\% higher when salt was fed away from water. Conversely, actual use in the heavy zone exceeded predicted use by about $6 \%$ when salt was fed at water, but was $5 \%$ lower than predicted when salt was fed away from water. Thus, differences due to treatment were about twice as great in the light zone as in the heavy zone.

will not supply it.

Average utilization for the pasture changed greatly from year to year and was related negatively to forage production. Utilization in the heavy-, medium-, and light-use zones averaged 69,50, and $23 \%$, respectively, for the 8 -year study period. Low herbage production in the heavy-use zone was associated with relatively higher utilization in all three zones, accounting for 72,85 , and $49 \%$ of the year-to-year fluctuations in use in the

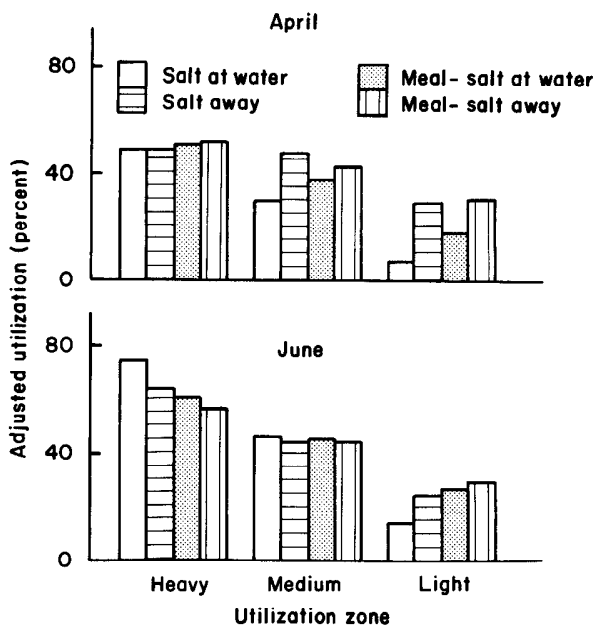

Fig. 3. Average utilization at the end of April and June for each treatment and use zone (mean of 2 years).

\section{Conclusions}

Cattle are not apt to eat dangerous amounts of salt if meal-salt is fed free choice a mile or more from water. Low intake of supplement may be a problem, however, where mixtures containing as much as $25 \%$ salt are fed far from water. remote parts of the range where forage is abundant will increase utilization of perennial grasses in such areas but will not greatly decrease use on areas closer to water.

Placement of salt or meal-salt alone distribution problem. In many cases, use reduced materially only by appropriate periods of deferment or rest.

\section{Literature Cited}

Ares, Fred N. 1936. How the use of salt obtains better forage utilization on a cattle range. Cattleman 22(12):1-3.

Ares, Fred N. 1953. Better cattle distribution through the use of meal-salt mix. J. Range Manage. 6:341-346.

Bentley, J. R. 1941. Automatic recording of salting and watering habits of cattle. J. Forest. 39:832-836.

Cardon, B. P., E. B. Stanley, W. J. Pistor, and J. C. Nesbitt. 1951. The use of salt as a regulator of supplemental feed intake and
Placing salt or meal-salt mixtures on cannot be expected to cure a serious on heavily grazed areas near water can be 
its effect on the health of range livestock. Ariz. Agr. Exp. Sta. Bull. 239. 15 p. illus.

Chapline, W. R., and M. W. Talbot. 1926. The use of salt in range management. U.S. Dep. Agr. Circ. 379. 32 p.

Culley, Matt. 1938. Grazing habits of range cattle. Amer. Cattle Prod.
$\mathrm{XIX}(8): 3,4,16,17$.

Roach, Mack E. 1950. Estimating perennial grass utilization on semidesert cattle ranges by percentage of ungrazed plants. J. Range Manage. 3:182-185.

Skovlin, Jon M. 1965. Improving cattle distri- bution on western mountain rangelands. U. S. Dep. Agr. Farmer's Bull. 2212. 14 p.

Zeno, Tesfay, and James 0 . Klemmedson. 1970. Behavior of fistulated steers on a desert grassland. J. Range Manage. 23:158-163. 